\title{
Coexistence of squamous cell tracheal papilloma and carcinoma treated with chemotherapy and radiotherapy: a case report
}

This article was published in the following Dove Press journal:

Therapeutics and Clinical Risk Management

21 December 2015

Number of times this article has been viewed

\author{
Dimitrios Paliouras,' \\ Apostolos Gogakos,' \\ Thomas Rallis,' Fotios \\ Chatzinikolaou, ${ }^{2}$ Christos \\ Asteriou,' Georgios \\ Tagarakis, ${ }^{3}$ John Organtzis, ${ }^{4}$ \\ Kosmas Tsakiridis, ${ }^{5}$ Drosos \\ Tsavlis, ${ }^{4}$ Athanasios \\ Zissimopoulos, ${ }^{6}$ loannis \\ Kioumis, ${ }^{4}$ Wolfgang \\ Hohenforst-Schmidt, ${ }^{7}$ \\ Konstantinos Zarogoulidis, ${ }^{4}$ \\ Paul Zarogoulidis, ${ }^{4}$ \\ Nikolaos Barbetakis' \\ 'Thoracic Surgery Department, \\ Theagenio Cancer Hospital, \\ ${ }^{2}$ Department of Forensic Medicine \\ and Toxicology, Faculty of Medicine, \\ ${ }^{3}$ Department of Cardiothoracic \\ Surgery, AHEPA University Hospital, \\ ${ }^{4}$ Pulmonary Department-Oncology \\ Unit, "G. Papanikolaou" General \\ Hospital, Aristotle University of \\ Thessaloniki, ${ }^{5}$ Cardiothoracic Surgery \\ Department, "Saint Luke" Private \\ Hospital, Panorama, Thessaloniki, \\ ${ }^{6}$ Nuclear Medicine Department, \\ University General Hospital of \\ Alexandroupolis, Democritus \\ University of Thrace, Alexandroupolis, \\ Greece; ${ }^{7}$ Medical Clinic I, "Fuerth" \\ Hospital, University of Erlangen, \\ Fuerth, Germany
}

Correspondence: Paul Zarogoulidis Pulmonary Department-Oncology Unit,

"G. Papanikolaou" General Hospital,

Aristotle University of Thessaloniki,

Exohi 1100 , Thessaloniki, Greece

Tel +30 697727 I974

Fax +30 23। 0992424

Email pzarog@hotmail.com
Background: Papillomatosis presents, most frequently, as multiple lesions of the respiratory tract, which are usually considered benign. Malignant degeneration into squamous cell carcinoma is quite common, although curative approaches vary a lot in modern literature.

Case report: We report a case of a 66-year-old male patient with the coexistence of multiple squamous cell papilloma and carcinoma in the upper trachea with severe airway obstruction that was diagnosed through bronchoscopy and treated by performing an urgent tracheostomy, followed by concurrent chemotherapy and radiotherapy. There was no evidence of recurrence after a 12-month follow-up period.

Conclusion: This study underlines the diagnostic and therapeutic value of bronchoscopy as well as multimodality palliative treatment in such cases. To the best of our knowledge, this is the first study to describe an immediate treatment protocol with tracheostomy and concurrent chemotherapy/radiotherapy in a patient with squamous cell tracheal papilloma and carcinoma.

Keywords: papilloma, trachea, squamous cell carcinoma

\section{Introduction}

Primary tracheal malignancies are extremely rare, with an incidence of approximately 0.1 in every 100,000 persons per year. ${ }^{1}$ Recurrent respiratory papillomatosis (RRP) is a primary benign disease caused by the human papilloma virus (HPV), predominantly HPV-6 and -11. It usually occurs as multiple lesions in the oral cavity, the larynx, and the subglottic segment of the trachea and is more common in children than adolescents. ${ }^{2}$ In 3\%-5\% of patients, RRP may undergo malignant transformation into squamous cell carcinoma (SCC), with a relatively poor prognosis. ${ }^{1}$ Specific types of HPV are strongly believed to be involved. However, the mechanism of malignant degeneration still remains to be examined. ${ }^{3,4}$

\section{Case presentation}

A 66-year-old male patient, with Eastern Cooperative Oncology Group score 1-2, was admitted to our clinic. Written, informed consent was obtained from the patient. Ethical approval was obtained from the Institutional Review Board (IRB) of "Theageneio" Anticancer Hospital, Thessaloniki, Greece. His major symptoms were dyspnea on exertion with stridor, cough, and mild hemoptysis over the past 2 months. His medical record was long; starting in 1977, when he had undergone surgical removal of an anterior chest wall dermatofibrosarcoma, for which he received adjuvant radiotherapy with a total dose =5,500 Gy. He developed locally advanced skin necrosis that was attributed to former irradiation of the area, 25 years later. He subsequently underwent an esthetic 

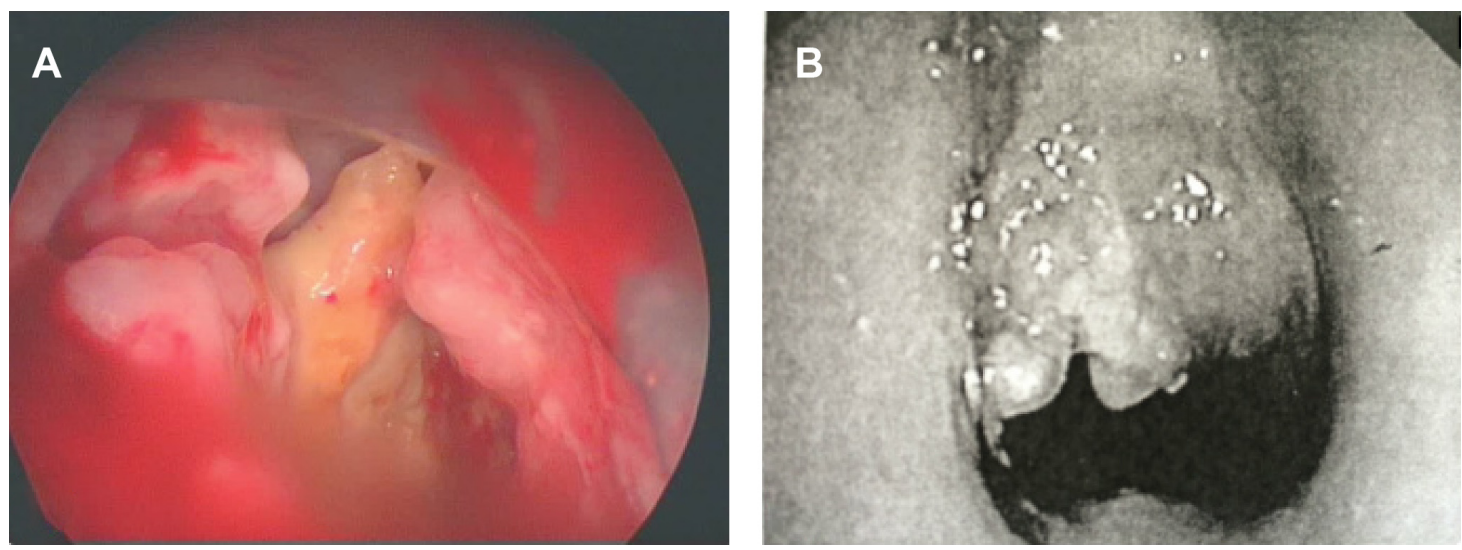

Figure I (A) Rigid bronchoscopy revealed multiple intraluminal lesions in the upper trachea. (B) Lesions resulting in severe central airway obstruction.

reconstruction with the use of distant flap. He was also a heavy smoker of 70 pack-year and was treated for hypertension.

Cervical and chest computed tomography (CT) scan upon admission revealed multiple lesions in a $5 \mathrm{~cm}$ area in the upper trachea. Cervical and mediastinal lymph nodes were within normal limits. Laboratory values indicated slightly elevated white blood cell count $\left(10.3 \times 10^{9} / \mathrm{L}\right)$, with $83.7 \%$ neutrophils. Physical examination revealed a normal temperature of $36.9^{\circ} \mathrm{C}$; oxyhemoglobin saturation was at $88 \%$ breathing room air, while respiratory rate was 18 breaths/min.

The patient underwent bronchoscopy under general anesthesia with a rigid bronchoscope, where multiple intraluminal lesions were visualized in the upper trachea (Figure 1A). The lesions resulted in $\sim 80 \%$ central airway obstruction, which prevented the passage of the rigid bronchoscope (Figure 1B). Multiple biopsies were taken, followed by laser ablation of the lesions. Pathology revealed squamous cell papillomatosis with local degeneration into squamous cell carcinoma.

One week post-laser ablation, the lesions recurred causing tracheal stenosis and severe dyspnea. An urgent tracheostomy was performed, with removal of a fibrous tissue lesion that caused severe airway obstruction above the carina, resulting in a remarkable improvement in the patient's breathing condition. Meanwhile, the patient's case was discussed by the Thoracic Oncology board of "Theageneio" Anticancer Hospital. Concurrent chemotherapy along with radiotherapy of the trachea was decided. The patient started chemotherapy at a plan of cisplatin $70 \mathrm{mg} / \mathrm{m}^{2}$ once weekly for 3 weeks, as well as radiotherapy of the trachea and the upper mediastinum at a total dose $=2,000 \mathrm{~Gy} / \mathrm{FD}=400 \mathrm{~Gy}$ in a sitting position.

One month post-chemotherapy and radiotherapy, the patient was re-examined through bronchoscopy under general anesthesia with a rigid bronchoscope, which revealed complete elimination of the intraluminal lesions (Figure 2).
The patient was discharged from "Theageneio" Anticancer Hospital, experiencing only moderate pain when swallowing due to radiation-induced esophagitis, as was revealed by an upper gastrointestinal endoscopy that was performed. The patient entered a follow-up with cervical and chest CT scan along with bronchoscopy every 6 months. One year later, no evidence of recurrence was noted.

\section{Discussion}

Primary tracheal malignancies are rarely observed, as they most commonly result from direct spread of neighboring tumors. SCC along with adenoid cystic carcinoma make up approximately two-thirds of adult primary tracheal tumors, with an incidence of approximately 0.1 in every 100,000 persons per year. ${ }^{1}$ Recurrent respiratory papillomas are benign tumors caused by HPV types 6 and 11, with an incidence of 1.8 in every 100,000 persons per year. ${ }^{2,3}$ They usually occur in children $<5$ years (juvenile-onset RRP), and less commonly in elderly patients between the 3 rd and 4 th decade of their lives (adult-onset RRP). ${ }^{1}$ RRP malignant degeneration

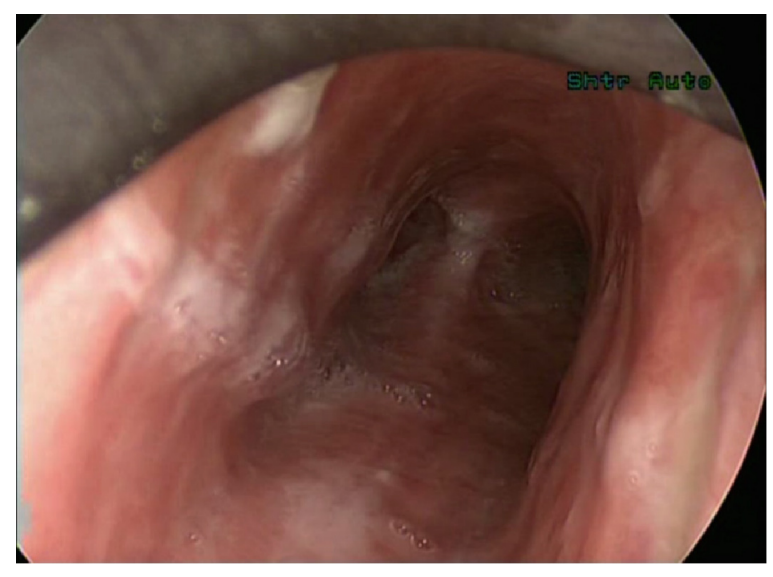

Figure 2 Bronchoscopic findings after chemotherapy and radiotherapy. 
to SCC is extremely rare, with less than 50 cases having been reported in the literature. ${ }^{1}$ Trachea is the next most commonly involved site after larynx. ${ }^{1}$ RRP occurs in $3 \%-5 \%$ of patients, with a relatively poor prognosis of 5- and 10-year survival rates at $5 \%-15 \%$ and $6 \%-7 \%$, respectively. ${ }^{1}$

DiMarco et al were the first to report the presence of the multiple RRP of the tracheobronchial tree with malignant degeneration, in $1978 .^{5}$

RRP degeneration to SCC is strongly related to smoking, irradiation, and carcinogenic factor exposure. ${ }^{3,4}$ Moreover, the association of specific types of HPV infection with malignant transformation has been reported by previous studies. HPV types 11, 16, and 18 are most commonly associated with a higher risk of developing SCC. ${ }^{4,6}$ Furthermore, in 1998, Rady et al, concluded that an endogenous type of mutation of the p53 anti-oncogene is strongly related to RRP malignant transformation. ${ }^{7}$ Five years later, a study by Go et al, revealed that p53 is not a safe molecular marker for monitoring the transformation process in patients with RRP. It is therefore becoming evident that the mechanism of RRP malignant degeneration to SCC is not yet fully understood.

The main symptoms of patients with RRP are dyspnea and hoarseness, cough, hemoptysis and occasionally severe airway obstruction that can prove fatal. ${ }^{1}$

Several treatment protocols and techniques have been reported in modern literature. RRP degeneration in the trachea is primarily treated with surgery with new, innovative techniques, such as video-assisted thoracoscopic surgery, making their way in modern curative approaches. ${ }^{9,10}$ Other treatments include the use of argon plasma coagulation, intralesional injection of cidofovir, ethanol injection therapy, photodynamic treatment and, recently, systemic treatment with bevacizumab, offering valuable additions in the treatment strategy of RRP malignant degeneration. ${ }^{11-14}$

In our current study, we report the case of a 66-year old male with the coexistence of RRP and SCC in the trachea, causing severe airway obstruction that was treated by performing an urgent tracheostomy, followed by concurrent chemotherapy and radiotherapy. The diagnosis was achieved by rigid bronchoscopy. Eventually, the patient had an excellent long-term outcome; there was no evidence of recurrence, as was established through bronchoscopy and CT scanning in a follow-up period of 1 year. Nevertheless, the cause of local degeneration of papillomas into carcinoma still remains unknown. However, the fact that the patient had undergone chest wall irradiation for dermatofibrosarcoma should be taken under serious consideration. To the best of our knowledge this is the first case reported in the literature to describe an immediate treatment protocol with tracheostomy and concurrent chemotherapy/radiotherapy in a patient with squamous cell tracheal papilloma and carcinoma.

\section{Conclusion}

This study underlines the diagnostic and therapeutic value of bronchoscopy as well as a multimodality palliative treatment in cases with locally advanced malignant degeneration of RRP. Frequent follow-up of such cases is recommended. However, surgical involvement is necessary, when needed.

\section{Disclosure}

The authors report no conflicts of interest in this work.

\section{References}

1. Junker K. Pathology of tracheal tumors. Thorac Surg Clin. 2014;24(1): $7-11$.

2. Shibuya H, Kutomi T, Kujime K, Hara K, Hisada T. An adult case of multiple squamous papillomas of the trachea associated with human papilloma virus type 6. Intern Med. 2008;47(17):1535-1538.

3. Guillou L, Sahli R, Chaubert P, Monnier P, Cuttat JF, Costa J. Squamous cell carcinoma of the lung in a nonsmoking, nonirradiated patient with juvenile laryngotracheal papillomatosis. Evidence of human papillomavirus-11 DNA in both carcinoma and papillomas. Am J Surg Pathol. 1991;15(9):891-898.

4. Popper HH, el-Shabrawi Y, Wockel W, et al. Prognostic importance of human papilloma virus typing in squamous cell papilloma of the bronchus: comparison of in situ hybridization and the polymerase chain reaction. Hum Pathol. 1994;25(11):1191-1197.

5. DiMarco AF, Montenegro H, Payne CB Jr, Kwon KH. Papillomas of the tracheobronchial tree with malignant degeneration. Chest. 1978; 74(4):464-465.

6. Lin HW, Richmon JD, Emerick KS, et al. Malignant transformation of a highly aggressive human papillomavirus type 11-associated recurrent respiratory papillomatosis. Am J Otolaryngol. 2010;31(4):291-296.

7. Rady PL, Schnadig VJ, Weiss RL, Hughes TK, Tyring SK. Malignant transformation of recurrent respiratory papillomatosis associated with integrated human papillomavirus type 11 DNA and mutation of p53. Laryngoscope. 1998;108(5):735-740.

8. Go C, Schwartz MR, Donovan DT. Molecular transformation of recurrent respiratory papillomatosis: viral typing and $\mathrm{p} 53$ overexpression. Ann Otol Rhinol Laryngol. 2003;112(4):298-302.

9. Terlinden N, Van Boven M, Hamoir M, Schmitz S. An innovative approach to tracheotomy in patients with major obstruction of the upper airway. Am J Otolaryngol. 2014;35(3):445-448.

10. Zhao G, Dong C, Yang M, Du X, Hu X. Totally thoracoscopic tracheoplasty for a squamous cell carcinoma of the mediastinal trachea. Ann Thorac Surg. 2014;98(3):1109-1111.

11. Lott DG, Krakovitz PR. Squamous cell carcinoma associated with intralesional injection of cidofovir for recurrent respiratory papillomatosis. Laryngoscope. 2009;119(3):567-570.

12. Shimoda K, Shiraishi Y, Harano T, Hiramatsu M, Kita H, Katsuragi N. [Remarkable improvement in dyspnea following bronchofiberscopic ethanol injection therapy - a case report]. Gan To Kagaku Ryoho. 2013; 40(12):2339-2341. Japanese.

13. Sokolov VV, Gladyshev AA, Telegina LV, et al. [Combined endolaryngeal videoendoscopic surgery and photodynamic treatment of patients with recurrent laryngeal and tracheal papillomatosis]. Vestn Otorinolaringol. 2007;(6):4-9. Japanese.

14. Mohr M, Schliemann C, Biermann C, et al. Rapid response to systemic bevacizumab therapy in recurrent respiratory papillomatosis. Oncol Lett. 2014;8(5):1912-1918. 


\section{Publish your work in this journal}

Therapeutics and Clinical Risk Management is an international, peerreviewed journal of clinical therapeutics and risk management, focusing on concise rapid reporting of clinical studies in all therapeutic areas, outcomes, safety, and programs for the effective, safe, and sustained use of medicines. This journal is indexed on PubMed Central, CAS,

EMBase, Scopus and the Elsevier Bibliographic databases. The manuscript management system is completely online and includes a very quick and fair peer-review system, which is all easy to use. Visit http://www.dovepress.com/testimonials.php to read real quotes from published authors.

Submit your manuscript here: http://www.dovepress.com/therapeutics-and-clinical-risk-management-journal 